\title{
Antitumor Activity of Novel Azoles on Ehrlich Ascites Carcinoma Cells in Mice
}

\author{
Fawiza Zakaria ELAblack ${ }^{1 *}$, Usama Bahgat Elgazzar ${ }^{2}$ and Ahmed Elsehily ${ }^{1}$ \\ ${ }^{1}$ Department of Organic chemistry, Damietta University, Egypt \\ ${ }^{2}$ Department of Medical Biochemistry, Al-Azhar University, Egypt
}

*Corresponding author: Fawiza Zakaria ELAblack, Department of Organic chemistry, Faculty of Science, Damietta University, Egypt.

Received Date: February 04, 2020

Published Date: February 21, 2020

\begin{abstract}
s
Purpose: The main objective of the present work was to investigate, for the first time, the antitumor effect, lipid peroxidation, nitrosative stress and antioxidant status of organic heterocyclic Triazole derivatives.

Method: The antitumor activity of Triazole derivatives was evaluated against Ehrlich ascites carcinoma (EAC) bearing mice as a model for the cancer at doses of 10 and $15 \mathrm{mg} / \mathrm{kg}$ body weight, while acute toxicity studies were performed to determine the safety of the compound. Briefly, A total of 105 female Swiss albino mice were divided into 7 groups $(n=15)$, the EAC cells were injected (i.p.) into sixty female mice (in 4 equal groups), and after a one day incubation period, Azole injected with in a dose (10 and $15 \mathrm{mg} / \mathrm{kg}$ body wt. day after day). After 10 days, ten animals in each group were sacrificed for observation of antitumor activity and the remaining animals were observed to determine host the life span. Antitumor effect was determined by evaluation of tumor volume, viable tumor cell count of the host, determination of apoptosis-related proteins P53 and Bcl2 levels, Malondialdehyde (MDA), Nitric oxide (NO) and reduced glutathione (GSH) in Liver tissue. The standard antitumor used was cisplatin.
\end{abstract}

Results: Administration of Azole in a dose of 10,15 mg significantly decreased EAC cells volume and count in a dose-dependent manner. Furthermore, Significant $(p<0.001)$ decrease in MDA and NO levels Meanwhile GSH was significantly $(p<0.001)$ increased. P53 highly significantly $(\mathrm{p}<0.001)$ increased while Bcl2 level highly significant $(\mathrm{p}<0.001)$ decreased after treatment with Azole 10,15 mg. Moreover, injection with Azole 10 and $15 \mathrm{mg}$ highly significantly $(\mathrm{p}<0.001$ ) increased AST, ALT and ALP activity.

Conclusion: The results suggest that Azole exhibit significant antitumor activity in Ehrlich ascites carcinoma (EAC) bearing mice that is comparable to that of the reference standard, cisplatin. But, has a hepatorenal toxic effect.

\section{Introduction}

Benzimidazole being an isostere of purine based nucleic acid and an important scaffold in various biologically active molecules is widely explored for development of anticancer agents [1]. The versatility of new generation benzimidazole would represent a fruitful pharmacophore for further development of better medicinal agents [2]. Thus, benzimidazole-derived moieties' introduction to the drug design may enhance the biological activities. As, triazoles are safe for most patients; their use in medically complex cases can be complicated further by dose-limiting toxicities and pharmacokinetic drug-drug interactions Cancer is a severe metabolic syndrome and is one of the leading causes of death regardless of developments in the tools of disease diagnosis, treatment and prevention measures $[3,4]$. Cancer development and progression, programmed cell death (apoptosis) and the genes regulating this process involved in tissue and organ homeostasis and loss of the apoptotic process is often associated with tumour expansion, Alterations in the expression of proteins involved in intracellular apoptotic pathways are a potential cause of neoplastic expansion, so the earliest and most specific tumour markers are usually detectable at the intracellular level [5]. When exposure the cells to the external damage stimuli, they activate the regulation of expression of P53 and Bcl-2 genes. P53 tumor suppressor protein acts as a protector of genomic activity by inducing either cell cycle arrest (at G1 and/or G2 phase) or apoptosis. Bc1-2 gene is an anti-apoptotic protein, participate in the p53 apoptotic pathway and the equilibrium between those positively and negatively regula-tory proteins is essential for the 
susceptibility to apoptosis. A high level of Bcl-2 expression prevents cells from apoptosis caused by cytotoxic factors or cellular stress [6]. Ehrlich ascites carcinoma (EAC) considered as an experimental tumor modeling. EAC is referred to as an undifferentiayrd carcinoma and is originally hyper diploid, has high transplantable capability, no-regresion, rapid proliferation, shorter life span, $100 \%$ malignanc, and resembles human tumors which are the most sensitive to chemotherapy due to they are undifferentiated and have a rapid growth rate [7] Development and identification of compounds capable of killing transformed or cancer cells, without being toxic, is of utmost importance, and has gained the increasing interest of scientists worldwide [8]. The major side effect associated with various anticancer or anti-proliferative agents is cytotoxicity towards normal cells due to lack of selectivity for the abnormal cells. Therefore, search on anticancer agent has been in continuum since many years [9]. Cisplatin is one of the most compelling chemotherapy drugs that are widely used for cancer. It was the first FDA-approved platinum compound for cancer treatment in 1978 [10]. Common side effects for using Cisplatin include bone marrow suppression, hearing problems, kidney problems, and vomiting. Other serious side effects include numbness, trouble walking, allergic reactions, electrolyte problems, and heart disease. Use during pregnancy is known to harm the baby [11]. However, the severe side effects and resistance by the cancer cells confine their clinical application widely. To curb increasing resistance and the unbearable cost of treatment, it is a necessity to design potential alternatives [12]. Benzimidazole derivatives have demonstrated as potential new therapeutics for the treatment of cancer in vitro and in vivo [13]. The present study was carried out to investigate the anti-tumor activity of newly synthesised azoles in comparison with cisplatin against Ehrlich ascites carcinoma in Swiss albino mice.

\section{Materials and Methods}

\section{Experimental animals}

Studies were carried out using a total of 75 male Swiss albino mice weighting 22- 25 g obtained from Animal House of National Research Center, Giza, Egypt. The experimental animals were housed 15 per cage in a room with 65\% humidity, 12:12 h light: dark cycle at ambient temperature of $20 \pm 1$ _C. Standard diet, commercial feed pellets and tap water were freely available (Figure 1).

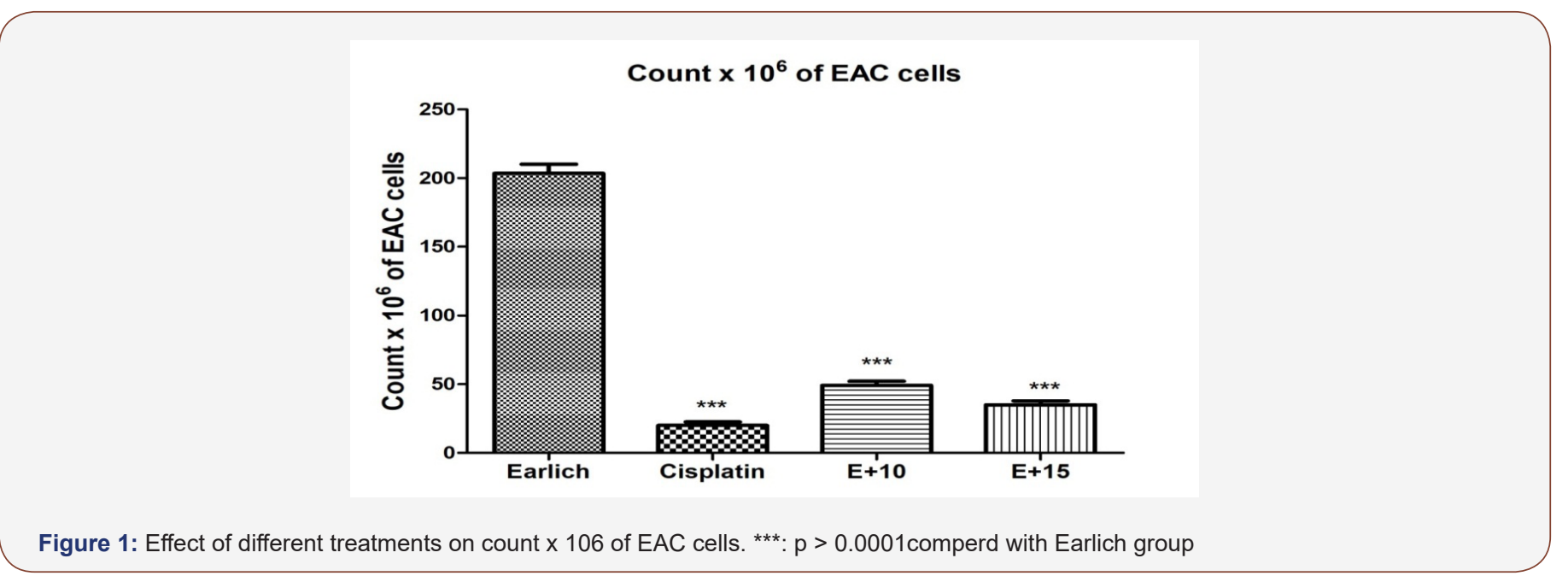

\section{Tumor cells}

Ehrlich ascites carcinoma (EAC) cells were obtained from Cancer Biology Section, National Cancer Institute, Cairo, Egypt. The Ehrlich tumor line was maintained, till the time of the experiment in female Swiss albino mice by serial intraperitoneal passage of $2.5 \times 10^{6}$ cells/mouse at 7-10 days intervals (Figure 2).

\section{Standard anticancer drug}

Cisplatin (CDDP) is a Platinum compound (cisDiamminedichloroplatinum), [14]. it was used as a standard anticancer drug. Cisplatin (MYLAN $10 \mathrm{mg}), 10 \mathrm{ml}(1 \mathrm{mg} / \mathrm{ml})$ ) was injected intraperitoneally to mice at a dose of $10 \mathrm{mg} / \mathrm{kg}$ body weight [15] (Figure 3).

\section{Experimental design}

A total of 105 female Swiss albino mice were divided into 7 groups $(\mathrm{n}=15)$ with an average weight $22-25$ gm each as follows:

- G1: (negative control): injected intraperitoneally (I.P) with sterile saline ( $0.2 \mathrm{ml} /$ mouse day after day for 10 days).

- $\quad$ G2 (Damson control): injected (I.P) with sterile Damson $(0.2 \mathrm{ml} /$ mouse day after day for 10 days).

- $\quad$ G3 (Positive control): was inoculated (I.P) with EAC cell line $\left(2.5 \times 10^{6}\right.$ cells/mouse, $0.2 \mathrm{ml} /$ mouse $)$.

- $\quad$ G4 (Azole control): injected with Azole alone in a dose (10 $\mathrm{mg} / \mathrm{kg}$ body wt., $0.2 \mathrm{ml}$ / mouse day after day for 10 days). 
- $\quad$ G5 (EAC + cisplatin): were inoculated (I.P) with (EAC) like the EAC control group, then injected with cisplatin in a dose (10 $\mathrm{mg}$ / kg body wt. , $0.2 \mathrm{ml} /$ mouse day after day day for 10 days) as standard anticancer drug for 10 days.
- $\quad$ G6 (EAC + Azole $10 \mathrm{mg}$ ): injected with Azole in a dose (10 $\mathrm{mg} / \mathrm{kg}$ body wt., $0.2 \mathrm{ml}$ /mouse day after day for 10 days) after inoculation (I.P) with (EAC).

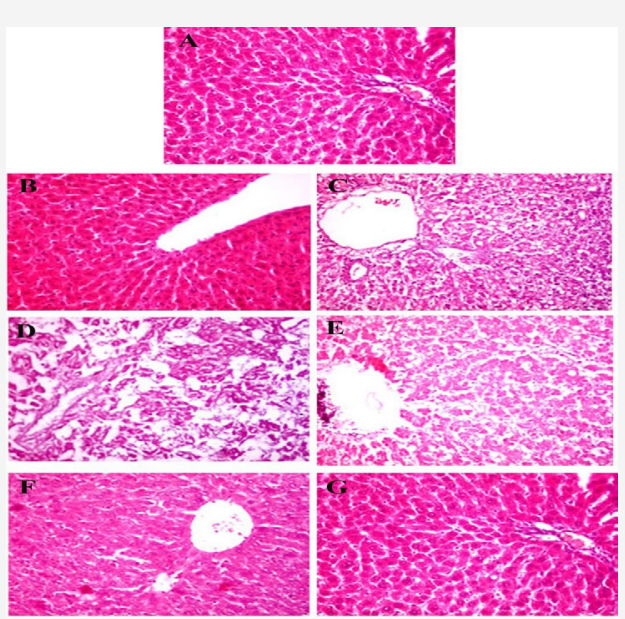

Figure 2: Effect of different treatments on Histological picture of rat liver. (A) Negative control saline. (B) Damson like negative control saline. (C) Earlish with cisplatin: Showing restoration of hepatic architecture with focal hemorrhage. (D) Earlish Positive control. The degenerative and proliferative lesions and showed some histologic lesions such as individual hepatocellular necrosis, cellular vacuolation, and spongiosis hepatitis changes. (E) Earlis with $10 \mathrm{mg}$ Azole: revealed dilatations in sinusoids and cystic degeneration (characterized by large empty spaces in the parenchyma) secondary to hepatocellular dropout. (F) Earlish with $15 \mathrm{mg}$ Azole showing centrilobular hemorrhage with focal necrosis and complete distortion of architecture. (G) Partial restoration of architecture with inflammatory cells infiltrates.
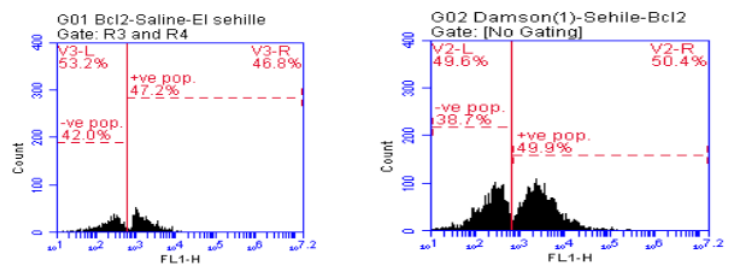

(normal control group)

(Damson group)
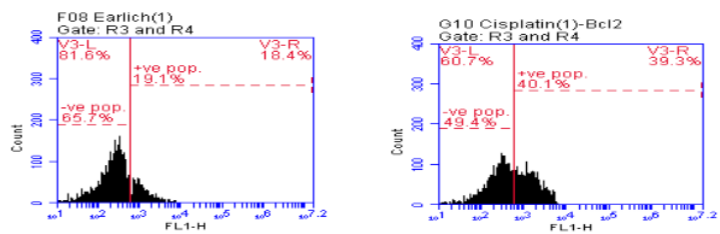

(EAC control group)

$(\mathrm{EAC}+$ cisplatin group)
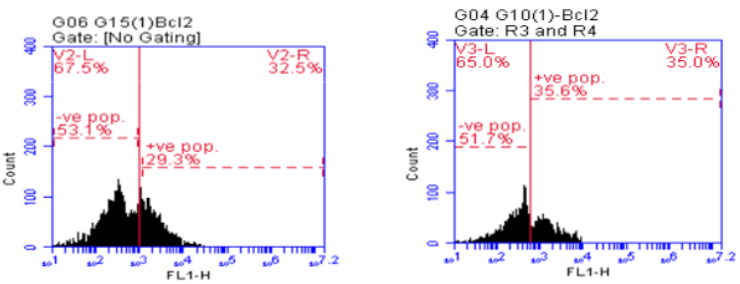

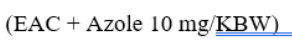

$(\mathrm{EAC}+$ Azole $15 \mathrm{mg} / \mathrm{KBW})$

Figure 4: Effect of different treatments on Bcl-2. Flow cytometric figures for DNA cycle analysis staining with propiduim iodide showing the three phases (G0/1,S phase and G2/M ) for Bcl-2.These figures showed no different between the phases of cell cycle, while the apoptosis $\%$ showed highly significant percent of cells referring to the other cell cycle phases which showed low \% of cell in G0/1 than apoptosis and S Phase $\%$ also showed highly $\%$ of cells than the first four samples. (M1= apoptosis $\%, M 2=G 0 / 1, M 3=S \%$ and $M 4=G 2 / M$ ). 
- $\quad$ G7 (EAC + Azole 15 mg): injected with Azole in a dose (15 $\mathrm{mg} / \mathrm{kg}$ body wt., $0.2 \mathrm{ml}$ /mouse day after day for 10 days) after inoculation (I.P) with (EAC). After 10 days mice were euthanized to measure tumor cell count and other parameters (Figure 4).

\section{Antitumor evaluation}

Anti-tumor potential was evaluated by measuring tumor cell count and inhibition of EAC growth. Ascetic fluid of EAC tumor bearing mice was collected in a Wintrobe's tube. The total volume of fluid was measured and the total number of tumour cells was counted by the Trypan blue exclusion assay [16]. The total number of EAC cells was calculated by using the formula:

Total EAC count $=$ Mean number of unstained cells $\times$ volume of count samples $\times$ dilution $\times 10^{4} / \mathrm{ml}$

\section{Cell viability and Counting of EAC cells}

The viability of EAC cells was determined by the Trypan Blue Exclusion Method [17], where the total and viable cells (nonstained) were counted at magnification $\mathrm{x} 40$; as the number of cells/ ml was determined in studed groups.

\section{Body weight}

Body weights of the experimental mice were recorded both in the treated and control group at the beginning of the experiment (day 0 ) and sequentially on the $3^{\text {rd }}, 6^{\text {th }}$ and $9^{\text {th }}$ day during the treatment period.

Biochemical analysis: Blood samples were collected after overnight fasting for biochemical Analysis. Sera were separated by centrifugation at $3000 \mathrm{x}$ for $10 \mathrm{~min}$ at room temperature and kept frozen $\left(-25^{\circ} \mathrm{C}\right)$ until analysis. Serums aspartate aminotrasferase (AST), alanine aminotransferase (ALT) [18], Creatinine [19] and urea [20] were determined.

\section{Determination of Malondialdehyde (MDA), Nitric oxide (NO) and reduced glutathione (GSH)}

Liver MDA concentration was estimated in cell homogenate spectrophotometrically according to [21]. Cellular levels of NO were determined in liver cells homogenate spectrophotometrically according to [22] and GSH activity was determined also in liver cells homogenate spectrophotometrically according to [23].

\section{Determination of molecular markers}

Determination of apoptosis-related proteins P53 and Bcl2 levels in Liver tissue as a prognostic indicator for cancer was performed using Flow cytometry (FCM) technique [24]. Flow cytometric approach has allowed sensitive and specific intracellular antigen quantification at the single cell level. Detection of intracellular molecules is particularly relevant in diagnosis of neoplastic malignancies and in predictive medicine [5].

\section{Histopathology evaluation}

The remaining portion of the same liver tissue was dissected and fixed in 10\% formal saline embedded in paraffin, sectioned and stained with Hematoxylin and Eosin (H\&E)

\section{Statistical Analysis}

All statistical analyses were done by a statistical for social science package "SPSS" 22.0 for Microsoft Windows, SPSS Inc. and considered statistically significant at a two-sided $\mathrm{P}<0.05$. Numerical data were expressed as mean \pm SEM. The levels of markers were analyzed by ANOVA.

\section{Results}

\section{Determination of LD50}

Preliminary experiments were carried out on 6 main groups (10 mice/each dose/each group). Azole wase injected in different doses to find out the range of doses which cause zero and $100 \%$ mortality of animals. The groups of 10 animals each, compound was given i.p. in doses of 5, 10, 15, 20, 25 and $30 \mathrm{mg} / 100 \mathrm{~g}$ b.w for determination of LD50. The LD50 was evaluated by Spearman and Karber method [25] on groups of mice, each of 10 animals. The test compounds were administrated i.p. at different doses. The number of animals which died within $24 \mathrm{~h}$ was recorded.

The LD50 was then calculated by the application of the following formula:

$$
\mathrm{LD}_{50}=\mathrm{D}_{\mathrm{m}}-\frac{\sum(\mathrm{Z} \cdot \mathrm{d})}{\mathrm{n}}
$$

$\mathrm{Dm}=$ the dose by which killed all the mice in the group.

$\mathrm{Z}=$ Half the sum of the dead rats from 2 successive groups.

$\mathrm{d}=$ the difference between 2 successive doses.

$\mathrm{n}=$ number of animals in each group.

\section{Dose-response (most effective dose) on EAC Count}

It was cleared that the most effective doses were finding to be 10 and $15 \mathrm{mg} / \mathrm{kg}$ for azole and $10 \mathrm{mg} / \mathrm{kg}$ for cisplatin as this dose reduced the number of EAC cells in treated mice group up to $75.0 \%$ of EAC cells compared to positive control group.

\section{Viability, Counting of EAC cells and body weight}

Table 1: Effect of Cisplatin and Azole on tumor cell count, tumor volume and Body weights.

\begin{tabular}{|c|c|c|c|c|c|c|c|}
\hline \multirow{2}{*}{ Parameter } & \multirow{2}{*}{ Saline } & \multirow{2}{*}{ Damson } & \multirow{2}{*}{ Earlich } & \multirow{2}{*}{ Cisplatin } & EAC & EAC & \multirow{2}{*}{ Azol $10 \mathrm{mg}$} \\
\hline & & & & & 10 mg Azol+ & 15mg Azol+ & \\
\hline Tumor cell count (x106 cells/L) & 0 & 0 & $203.3 \pm 16.3$ & $20.0 \pm 6.3$ & $49.2 \pm 7.5$ & $35.0 \pm 7.7$ & 0 \\
\hline tumor cell volume (ml) & 0 & 0 & $4.8 \pm 0.8$ & $2.1 \pm 0.7$ & $3.0 \pm 0.7$ & $2.3 \pm 0.8$ & 0 \\
\hline
\end{tabular}




\begin{tabular}{|c|c|c|c|c|c|c|c|}
\hline Zero day $(\mathrm{gm})$ & $18.9 \pm 0.8$ & $20.2 \pm 0.2$ & $21.9 \pm .8$ & $21.8 \pm 0.4$ & $22.8 \pm 0.8$ & $22.3 \pm 0.7$ & $22.1 \pm 0.4$ \\
\hline 3th day $(\mathrm{gm})$ & $20.25 \pm 1.1$ & $21.4 \pm 0.46$ & $25.5 \pm 0.4$ & $24.6 \pm 0.7$ & $25.1 \pm 0.4$ & $24.6 \pm 0.5$ & $23.1 \pm 0.2$ \\
\hline 6th day $(\mathrm{gm})$ & $22.7 \pm 1.0$ & $23.9 \pm 0.4$ & $27.5 \pm 0.5$ & $27.4 \pm 0.5$ & $26.8 \pm 0.7$ & $25.6 \pm 0.5$ & $23.9 \pm 0.6$ \\
\hline 9th day (gm) & $24.4 \pm 0.5$ & $25.3 \pm 0.3$ & $29.5 \pm 0.5$ & $25.2 \pm 0.5$ & $25.5 \pm 0.7$ & $24.4 \pm 0.9$ & $25.0 \pm 0.5$ \\
\hline
\end{tabular}

Data represented as mean \pm standard division

Table 1 summarized effect of Azol 10, 15 and cisplatin on EAC cells volume and count. The mean volume of EAC in positive control group was found to be $4.8 \pm 0.8(\mathrm{ml})$ as reported by [26]. This value was significantly decreased by $37.5 \%, 52.08 \%$ and $56.25 \%$ in Azol $10,15 \mathrm{mg} / \mathrm{kg}$ and cisplatin treated groups; respectively. Also the mean count of EAC cells in the positive control group was found to be $203.3 \pm 16.3$ (x10 cells/L), which significantly decreased by $75.79 \%, 82.78 \%$ and $90.16 \%$ in Azol 10, $15 \mathrm{mg} / \mathrm{kg}$ and cisplatin treated groups; respectively, compared to positive control group. The mean body weight value in the positive control group was found to be increased $29.5 \pm 0.5$ (gm) involving the the tumour volume compared to negative control group $24.4 \pm 0.5$ (gm) while Azol 10, $15 \mathrm{mg} / \mathrm{kg}$ and cisplatin downregulated it near or as in the negative control group and Damson control group, 25.5 $\pm 0.7,24.4 \pm 0.9$ and $25.2 \pm 0.5$ respectively. It can be hypothesized that increased body weight in the positive control group was attributed to increased tumor growth volume but downregulated near or as in negative control group in treated groups due to tumor growth inhibiting property of Azol (Table 2).

Table 2: Biochemical study.

\begin{tabular}{|c|c|c|c|c|c|c|c|}
\hline & Saline & Damson & EAC & 10 mg Azole & EAC+Cisplatin & $\begin{array}{c}\text { EAC+ } 10 \mathrm{mg} \\
\text { Azole }\end{array}$ & $\begin{array}{c}\text { EAC }+15 \mathrm{mg} \\
\text { Azole }\end{array}$ \\
\hline AST (U/L) & $42.32 \pm 0.28$ & 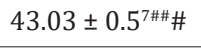 & $68.33 \pm 0.4^{6^{* *} *}$ & 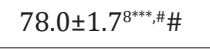 & 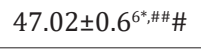 & 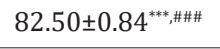 & 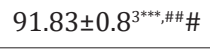 \\
\hline ALT (U/L & $49.55 \pm 0.75$ & 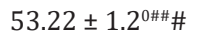 & $88.78 \pm 0.7^{8^{* *} *}$ & $84.87 \pm 1.0^{8^{* *} *}$ & 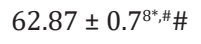 & 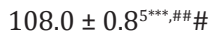 & 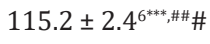 \\
\hline ALP (U/L) & $68.17 \pm 0.94$ & 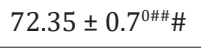 & $269.0 \pm 2.8^{5^{* *} *}$ & 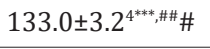 & $77.83 \pm 2.1^{5^{*}, \# \#}$ & 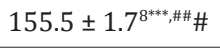 & 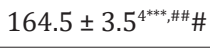 \\
\hline Createnine(mg/dL) & $0.61 \pm 0.02$ & 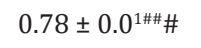 & $2.59 \pm 0.0^{7^{* * *} *}$ & 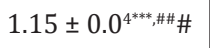 & 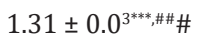 & 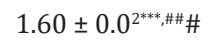 & 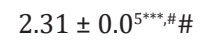 \\
\hline Urea (mg/dL) & $45.78 \pm 0.36$ & 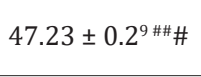 & $69.05 \pm 0.3^{9^{* *} *}$ & $\begin{array}{c}51.88 \pm \\
0.4^{7^{* * *}, \# \# \#}\end{array}$ & 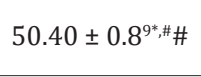 & 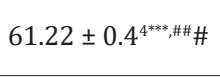 & 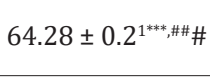 \\
\hline MDA (U/L) & $0.16 \pm 0.01$ & $0.17 \pm 0.01 \# \# \#$ & $0.51 \pm 0.02^{* * *}$ & $\begin{array}{c}0.34 \pm \\
0.05^{* * *}, \# \# \#\end{array}$ & $\begin{array}{c}0.17 \pm \\
0.01^{*}, \# \# \#\end{array}$ & $\begin{array}{c}0.33 \pm \\
0.01^{* * *}, \# \# \#\end{array}$ & $\begin{array}{c}0.29 \pm \\
0.01^{* * *}, \# \# \#\end{array}$ \\
\hline GSH (U/L) & $0.38 \pm 0.02$ & $0.37 \pm 0.01 \# \# \#$ & $0.10 \pm 0.01^{* * *}$ & $\begin{array}{c}0.28 \pm \\
0.03^{* * *}, \# \# \#\end{array}$ & $\begin{array}{c}0.30 \pm \\
0.02^{* *}, \# \# \#\end{array}$ & $\begin{array}{c}0.29 \pm \\
0.02^{* * *}, \# \# \#\end{array}$ & $\begin{array}{c}0.22 \pm \\
0.01^{* * *}, \# \# \#\end{array}$ \\
\hline NO (U/L) & $0.29 \pm 0.02$ & 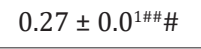 & $0.54 \pm 0.02^{* * *}$ & 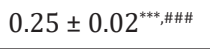 & 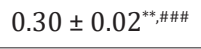 & 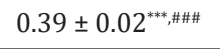 & 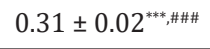 \\
\hline P53 (mg/dL) & $23.18 \pm 0.59$ & $21.68 \pm 0.79 \# \#$ & $13.81 \pm 0.39^{* * *}$ & $39.78 \pm 0.87^{* * *, \# \#}$ & $19.30 \pm 0.56^{* *}, \# \#$ & 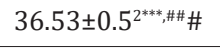 & 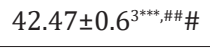 \\
\hline Bcl-2 (ng/mL) & $42.90 \pm 1.19$ & 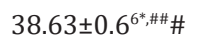 & $69.75 \pm 1.4^{7^{* *} *}$ & 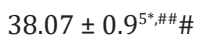 & 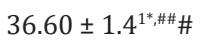 & 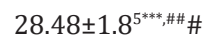 & 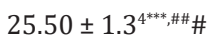 \\
\hline
\end{tabular}

Data presented as (Mean \pm SEM). ${ }^{*}{ }^{* *},{ }^{* * *}$ Significant at $p<0.05, p<0.01$ and $p<0.001$, respectively compared to normal control group. \#, \#\#, \#\#\# Significant at $p<0.05, p<0.01$ and $p<0.001$, respectively compared to EAC control group.

Life span prolongation: The mean life span prolongation in the positive control group was found yo be 16 days. Azole 10 and 15 mg treated groups showed unchanged and decreased the life span prolongation to 16 and 15 days respectively by $6.25 \%$ in a dose of $15 \mathrm{mg}(\mathrm{T} / \mathrm{C}$ ratio $=0.93 \% \mathrm{~T}=$ number of days the treated animals survived, $\mathrm{C}=$ number of days the control animals survived). As apparent from our data this unchanged or decreased life span was attributed to the hepatorenal toxic effect of the drug.

Liver function tests: AST, ALT and ALP activity in positive control group was significantly $(p<0.001)$ increased, compared to negative control group, while treatment with Azole 10 and 15 mg highly significantly $(\mathrm{p}<0.001$ ) increased them compared to negative and positive control groups, but cisplatin treatment slightly $(p<0.05)$ increases them compared to negative control group while significantly $(\mathrm{p}<0.001)$ decreases them for AST and $((p<0.01)$ for ALT and ALP compared to positive control group.
Moreover, injection with Azole 10 mg only significantly $(\mathrm{p}<0.001)$ increases them compared to negative and positive control groups, but there was no significant difference in ALT activity compared to positive control group. Also there was no significant effect of Damson vehicle on liver function tests.

Serum kidney functions: Serum creatinine and urea levels were significantly ( $\mathrm{p}<0.001$ ) increased in Azole 10,15 mg and cisplatin treated groups in addition to Azole $10 \mathrm{mg}$ only injected group, but cisplatin slightly $(\mathrm{p}<0.05)$ increases urea compared to negative control group. Meanwhile, treatment with Azole 10 and $15 \mathrm{mg}$ and cisplatin significantly $(\mathrm{p}<0.001)$ decreases them although Azole 15 mg $(\mathrm{p}<0.01)$ decrease creatinine and cisplatin decrease urea $(\mathrm{p}<$ 0.01 ), compared to positive control group. Moreover, injection with Azole 10 mg only significantly ( $p<0.001$ ) increases them compared to negative and positive control groups. But Damson vehicle had no significant effect of on kidney functions. 
MDA, NO and GSH levels: Positive control group showing significant increase of MDA and NOD levels ( $p<0.001$ ) while GSH significantly ( $p<0.001$ ) decreased compared to negative control group. Treatment with Azole 10, $15 \mathrm{mg}$ and cisplatin significantly ( $p<0.001)$ decreased MDA and NOD levels Meanwhile GSH was significantly $(\mathrm{p}<0.001)$ increased Compared to positive control group. Compared to negative control MDA and NOD levels still significantly increased in Azole 10, 15 mg groups and significantly decreased GSH $(\mathrm{p}<0.001)$. But in case of cisplatin MDA and NOD levels decrease, and GSH increased near as to the negative control group levels. Moreover, injection with Azole $10 \mathrm{mg}$ only significantly ( $p<0.001)$ increase of MDA and NOD levels while GSH showing significant $(\mathrm{p}<0.001)$ decreases compared to negative control group. Moreover, MDA, NO and GSH levels not affected significantly by Damson vehicle only.

P53 and Bcl2 levels: P53 significantly ( $p<0.001)$ decreased while Bcl2 significantly $(p<0.001)$ increased in Positive control group. Treatment with Azole 10 and 15 mg highly significantly ( $p$ $<0.001$ ) increased P53 compared to Positive and negative control groups, meanwhile cisplatin significantly ( $\mathrm{p}<0.01)$ increased compared to Positive and decreased compared to negative control groups. Bcl2 level highly significant $(\mathrm{p}<0.001)$ decreased after treatment with Azole 10,15 mg and cisplatin compared to Positive and negative control groups but in case of cisplatin decreased $(\mathrm{p}<$ 0.05 ) compared to negative control group. Furthermore, Damson vehicle had no significant effect on P53 but slight significant decreased $(p<0.05)$ Bcl2 level compared to negative control groups.

Histopathology of liver tissue: showed dilatations in sinusoids and cystic degeneration with secondary necrosis of endothelial and biliary epithelial cells in some of these areas after treatment with Azole 10. Azole15 mg treatment showed centrilobular hemorrhage with focal necrosis and complete distortion of architecture. Also cisplatin Showed restoration of hepatic architecture with focal hemorrhage. These were compared to positive control group which revealed some histological lesions such as individual hepatocellular necrosis, cellular vacuolation, spongiosis and hepatitis. In addition, Damson vehicle was like negative control saline.

\section{Discussion}

In the present investigation, the antitumor activity of the cisplatin and Novel Azoles were tested in vitro and in vivo against murine Ehrlich ascites carcinoma (EAC). In vivo cisplatin and Azoles were found to decrease the viability and count of viable cells of Ehrlich Ascites Carcinoma bearing mice when injected intraperitoneal in EAC bearing mice. Cisplatin mode of action has been linked to its ability to crosslink with the purine bases on the DNA; interfering with DNA repair mechanisms, causing DNA damage, and subsequently inducing apoptosis in cancer cells [27]. Imidazole as antimetabolites can be used in cancer treatment, as they interfere with DNA production and therefore cell division and the growth of tumors. These are the chemicals which become the building blocks. It was considered as Azole derivatives act as free radical scavengers and antioxidants, inhibiting lipid peroxidation and oxidative DNA damage, the phenolic $(-\mathrm{OH})$ plays a major role in the activity of Azole derivatives of DNA. They prevent these substances becoming incorporated in to DNA during the S phase of the cell cycle, stopping normal development and division [28] Various anticancer agents (also referred as antitumor, antiproliferative and antineoplastic) reported for treatment of varied kinds of cancers act through different mechanisms [29]. Anticancer drugs designed to block chromosome functioning may work much more effectively than targeted anticancer medicines that block the cytoplasmically located signaling pathways toward protein synthesis (cell growth). Imidazoles come under the category of antimetabolite which has specific mechanism of action in cancer. Antimetabolite is a type of chemical that inhibits the use of a metabolite. That's why these compounds are used as chemotherapy for cancer [30].

The aim of this study is to evaluate the antitumor activity of Novel Azoles in EAC tumor bearing mice. In EAC tumor, a regular rapid increase in ascitic tumor volume was observed. Ascitic fluid is the direct nutritional source for tumor cells and a rapid increase in ascitic fluid with tumor growth would be a means to meet the nutritional requirement of tumor cells [31]. The present study found that treatment with Azol 10 and $15 \mathrm{mg} / \mathrm{kg}$ significantly inhibite the tumor volume, viable tumor cell count and increased the life span of the tumor bearing mice to near normal levels in Azol treated animals. It may be concluded that Azol treatemt by decreasing the nutritional fluid volume and arresting the tumor growth has antitumor activity against EAC bearing mice.

Liver enzymes such as alanine aminotransferase (ALT), aspartate aminotransferase (AST) and alkaline phosphatase (ALP) are commonly used markers of hepatocellular injuries. They are capable of inducing alterations in membrane permeability properties of the liver. Serum elevation of ALP could occur due to blockage of bile ducts or impairment of bile production in the liver [32]. It is involved in transport of metabolites across cell membrane, protein synthesis, secretory activities and glycogen metabolism. It is a membrane bound enzyme and its alteration is likely to affect the membrane permeability and produce derangement in the transport of metabolites [33].

Current results revealed that the remarkable abundance of transaminases enzymes (AST and ALT) and ALP activities after treatment with Azole 10 and $15 \mathrm{mg}$ compared to negative and positive control groups, while cisplatin treatment decreased them near to the to negative control group. Accordingly, injection with Azole $10 \mathrm{mg}$ only significantly increases them compared to negative and positive control groups. In conclusion, the present study demonstrates that the Azole administration has a hepatotoxic effect of. Our biochemical findings were further supported by 
histopathological examination of liver sectioned which revealed degeneration, centrilobular hemorrhage with focal necrosis and complete distortion of architecture.

[34] Where found that Albendazole, Mebendazole or benzimidazole chemotherapy elevated liver transaminases in patients with echinococcosis. Moreover [12] found that, a new benzimidazole-derivatives complexes significantly elevated AST and ALT, GGT (Gamma-Glutamyl Transferase), ALP (Alkaline Phosphatase) and bilirubin in female animals. Cisplatin hepatotoxicity was recorded by increased serum ALT and AST activities. The present findings revealed that Azole treatment in a dose level of 10 and $15 \mathrm{mg}$ and cisplatin treatment reduced the elevated levels of serum creatinine and urea compared to positive control group, but cannot downregulate them compared to negative control group, these was attributed to be due to deterioration in renal function. As apparent from our data the Azole showed a nephrotoxic effect in a dose level of 15 more than $10 \mathrm{mg}$ and cisplatin Similar observation which supports this was reported by Zahran F. et al., [35] who also demonstrated that thiazole derivatives not recommended to be used in patients with renal impairment.

Cell damage caused by free radicals appears to be a major contributor to aging and to degenerative diseases of aging as cancer [36]. Oxidative stress is the set of intracellular and extracellular conditions that lead to chemical or metabolic generation of reactive species. The overall balance between factoes that exert oxidative stress and those that exhibit antioxidant capability [37]. An antioxidant may affect biological system by suppressing the formation of reactive oxygen species (ROS) and reactive nitrogen species (RNS), Thereby affecting other endogenous antioxidants, by preserving nitrous oxide (NO) activity or by sequestering transition metal ions [38]. Lipid peroxide formed in the primary site would be transferred through the circulation and provoke damage by propagating the process of lipid peroxidation [39].

As apparent from our data the treatment with Azol at a dose level of 10 and $15 \mathrm{mg} / \mathrm{kg}$ produced a simultaneous significant decrease in cellular MDA level along side a significant decrease of NO levels and increase of GSH activities in tumor target tissue. This could be explained in view of the work of [40] who demonstrated that positive correlation between erythrocyte MDA level with erythrocyte NO levels in patients with early stage non-small cell lung cancer. MDA which is a short-chain aldehyde and the free radical scavenging enzyme GSH used as biomarker of lipid oxidation and oxidative stress. MDA when present in excess due to its oxidative damage of cell membrane, lipoproteins and other lipid containing structures [41]. Increased lipid peroxidation in abnormally proliferating cells leads to an increase in serum MDA of patients with cancer [42]. Furthermore, Kaynar et al., [43] indicated that MDA was increased in carcinomatous tissue than in non disease organs. During cancer growth, GSH was decresd by oxidative stress which changes glutathione redox state of different tissues thereby increasing GSSG efflux from cells, this increase may be caused by an increase in peroxide production by tumor cells that can lead to oxidation of GSH within RBCs and different tissues [44].

Current results revealed that, treatment with Azol at a dose level of 10 and $15 \mathrm{mg} / \mathrm{kg}$ significantly $(\mathrm{p}<0.001)$ reduce cellular lipid peroxide MDA level and significant $(\mathrm{p}<0.001)$ increase in liver level of GSH compared to their negative control group. Also, treatment with cisplatin reduced MDA and elevated GSH levels near to the negative control group. The decrease in MDA and increase in GSH levels in tumor target cells along with the significant decrease in tumor volume and mean count of EAC cells in same groups, emphasizes the reduction in free radical yield and the subsequent decrease lipid peroxidation that leads to damage of the cell membrane. This explained by the work of [45] which revealed marked antioxidant activities of benzimidazole derivatives containing triazole, thiadiazole, morpholine ring, and carbothioamide moiety. Also, the increase in lipid peroxidation in cancer was attributed to be due to poor antioxidant system [46], also MDA acts as a tumor promoter and co-carcinogenic agent because of its high cytotoxicity and inhibitory action on protective enzymes $[47,48]$. This would explain our present findings and is also in agreement with it.

NO is produced from the amino acid L-Arginin in a reaction catalyzed by enzymes NOS., NO is a free radical having a short half-life and can react with superoxide anion 02-• producing peroxynitrite (ONOO-) anion, which can decompose to generate a strong oxidant such as the hydroxyl radical and can also induce sulphydryl oxidation and lipid peroxidation [49]. Peroxynitrite is cytotoxic and much more reactive than $\mathrm{NO}$ and $02-\bullet$ and causing different chemical reactions in biological system including nitration of tyrosine residues of proteins producing lipid peroxidation, which inhibits the mitochondrial electron transport, and oxidation of biological thiol compounds [50,51]. NO may play a dual role in tumor progression, as it can act as promoter or antitumor promoter, depending upon its concentration as reported by Eijan et al., [52]. Taysi et al., [53] showed that the concentration of NO, under non pathological conditions was found to be in the nanomolar range, but under conditions of oxidant injury it was found to be in the micromolar range. That is why we studied the changes of NO levels in tumor target cells after treatment using Azol at a dose level of 10 and $15 \mathrm{mg} / \mathrm{kg}$ in EAC-bearing mice. It was reported that EAC inoculation induced significant increase in the serum NO and MDA levels compared to that of the normal control group [50]. In the present study administration of Azol at a dose level of $10 \mathrm{mg} /$ $\mathrm{kg}$ produced significant depletion of NO level compared to that of EAC control group, while at dose and $15 \mathrm{mg} / \mathrm{kg}$ exhibited a highly significant decreased level of NO. This means that it acts in a dose dependent manner. This significant decrease in NO level, along with the observed decrease in tumor volume by treatment with Azol at different doses, suggests a positive association between the antitumor activity of Azol and NO levels or significantly inhibits the tumor growth. 
Our results are in agreement with [54] who reported that NO levels were significantly increased in tumor tissues of patients with colon cancer; others showed also that erythrocytes NO levels were significantly higher in patients with lung cancer than in controls [55]. This could be explained in view of the work provided by others [56], who indicated that elevated level of lipid peroxidation and its product MDA can stimulate host cells, mainly monocytes/ macrophages, to produce and release NO by the induction of inducible nitric oxide synthetase (iNOS) activity resulting in tissue as well as DNA damage. Similar observation which supports this was reported by [57], who found that NO concentration plays a role in tumor biology, and treatment with silymarin was suppress iNOS gene expression. This supports our postulation that Azol reduces NO production mainly via inhibition of iNOS activity and partly via increasing NO clearance.

Apoptosis (programmed cells death) is controlled by survival (some members of Bcl-2 family) and death (TNF and TNF receptor family members) factors, and can be induced following exposure to DNA damaging agents via p53 protein up-regulation [5]. Bcl-2 and p53 are two of the most important onco-related proteins. The Bcl-2 (B-cell CLL/lymphoma 2) protein is localised in the nuclear envelope, endoplasmatic reticulum and outer mitochondrial membrane [58] and its activity is regulated by phosphorylation through tyrosine kinases [59]. The Bcl-2 protein has been found to inhibit apoptosis by releasing of cytochrome-c from the mitochondria to the cytoplasm [60]. The Tumor protein p53 (TP53) up-regulates (i.e., increases) the expression of the two death genes, p21 and bax, whose encoded products are able to regulate growth arrest and apoptosis. It is a tumor suppressor protein and its functional inactivation is frequently observed in a wide range of human malignancies [61]. Functional p53 protein is also required for the efficient activation of apoptosis following irradiation or treatment with chemotherapeutic compounds [5]. Thus, the lack of p53 function leads to a dramatic increase in cellular resistance to these agents.

[62] repoted that Bcl-2 and p53 proteins involved in tumour progression, so these markers may had a prognostic utility; therefore it is preferabl to evaluate their expression at the cell level, [63], who indicated that, expression of Bcl-2 in some myeloid leukaemias, had a prognostic value related to the responsiveness to chemotherapy. P53 protein increased in several neoplastic malignancies for induction of apoptosis in DNA-damaged cells, and after radio- or chemo-therapy of tumour cells [5]. An inverse correlation was found between Bcl-2 and p53 proteins in our results, where treatment with Azol at a dose level of 10 and 15 $\mathrm{mg} / \mathrm{kg}$ exhibited more dramatic increase in the apoptotic protein p53 and a significant decrease in the anti-apoptotic protein Bc1-2 by more than two folds compared to negative and positive control groups but in a dose dependent manner and more significant than cisplatin treatment. We show herein, for the first time, that Azol at a dose level of 10 and $15 \mathrm{mg} / \mathrm{kg}$ injected to EAC bearing mice which received 2.5 millions of cells for tumor induction, showed a significant decrease in tumor volume and consequently significant antitumor activity. This reduction is also dose-dependent compared to their control group at the same experimental conditions. It could be deduced from the present prelimi $\neg$ nary findings that Azol has a potent antitumor activity. Tousson E. et al., [6] showed that $\mathrm{Bc} 1-2$ gene is an anti-apoptotic protein, participate in the p53 apoptotic pathway and the equilibrium between those positively and negatively regulatory proteins is essential for the susceptibility to apoptosis. A high level of Bcl-2 expression prevents cells from apoptosis caused by cytotoxic factors or cellular stress [64]. This would explain our present findings and is also in agreement with it. Accordingly the balance between cell proliferation and cell death develops cancer when it disrupted, and the ensuing aberrant proliferation leads to tumor growth. Furthermore, p21, found to be induced by p53 following stress and induction of p21 may cause cell cycle arrest. So p21 as a proliferation inhibitor is poised to play an important role in preventing and treating tumor development [65].

\section{Conclusion}

Using a novel Azol compounds have antitumor effect against EAC-cells induced by inhibiting EAC growth and induction of apoptosis in EAC bearing mice model and showed antioxidant activity. But, has a hepatorenal toxic effect. and as apparent Damson vehicle had no hepatorenal effect However, these treatment modalities deserve more investigations in the future.

\section{Acknowledgement}

None.

\section{Conflict of Interest}

No conflict of interest

\section{References}

1. Ali I, Lone MN, Aboul-Enein HY (2017) Imidazoles as potential anticancer gents. Med Chem Comm 8: 1742-1773.

2. Noor A, Qazi NG, Nadeem H, Khan AU, Paracha RZ, et al. (2017) Synthesis, characterization, anti-ulcer action and molecular docking evaluation of novel benzimidazole-pyrazole hybrids. Chemistry Central journal 11: 85-85.

3. Durstine J L, Gordon B, Wang, Z, Luo X (2013) Chronic disease and the link to physical activity. Journal of Sport and Health Science 2: 3-11.

4. Zhang L, Zhao S, Liang Z, Zhang J, Zhu W, et al. (2017) The colour tuning of upconversion emission from green to red in NaScF4:Yb3+/ Er3+ nanocrystals by adjusting the reaction time. Journal of Alloys and Compounds 699: 1-6.

5. Zamai L, Canonico B, Gritzapis A, Luchetti F, Felici C, et al. (2002) Intracellular detection of $\mathrm{Bcl}-2$ and p53 proteins by flow cytometry: Comparison of monoclonal antibodies and sample preparation protocols. Journal of biological regulators and homeostatic agents 16(4): 289-302.

6. Ehab Tousson, Ezar Hafez, Somia Zakia, Amani Gad (2014) P53, Bcl-2 and CD68 expression in response to amethopterin-induced lung injury and ameliorating role of L-carnitine; Pharmacotherapy 68: 631-639.

7. Mehmet O, Isik D K, Ibrahim HK, Muhammed EG (2011) Erlich Ascites Carcinoma. African Journal of Biotechnology 10(13): 2375-2378. 
8. Hashemzaei M, Delarami Far A, Yari A, Heravi RE, Tabrizian K, et al. (2017) Anticancer and apoptosis-inducing effects of quercetin in vitro and in vivo. Oncology reports 38: 819-828.

9. Iqbal J, Abbasi BA, Mahmood T, Kanwal S, Ali B, et al. (2017) Plantderived anticancer agents: A green anticancer approach. Asian Pacific Journal of Tropical Biomedicine 7: 1129-1150.

10. Kelland L (2007) The resurgence of platinum-based cancer chemotherapy. Nat Rev Cancer 7: 573-584.

11. American Society of Health-System Pharmacists. Archived from the original on 21 December (2016). Retrieved 8 December.

12. AlAjmi M F, Hussain A, Rehman MT, Khan AA, Shaikh PA, et al. (2018) Design, Synthesis, and Biological Evaluation of Benzimidazole-Derived Biocompatible Copper (II) and Zinc(II) Complexes as Anticancer Chemotherapeutics. International journal of molecular sciences 19 1492.

13. Özdemir A, Uzunoğlu S, Çalışkan B, Banoğlu E, Ark M (2017) Anticancer activity of novel benzimidazole derivatives against MCF-7 cancer cells. The FASEB Journal 31: 934.910-934.910.

14. Matsusaka S, Nagareda T, Yamasaki H (2005) Does cisplatin (CDDP) function as a modulator of 5-fluorouracil (5-FU) antitumor action? A study based on a clinical trial. Cancer Chemotherapy Pharmacology 55 387-392.

15. George M, Era T, Sylva H, Michael L, Konstantinos A (2009) In vivo investigation of tolerance and antitumor activity of cisplatin-loaded PLGA-mPEG nanoparticles. European Journal of Pharmaceutics and Biopharmaceutics 71: 190-195.

16. Vaishali JM, Piyusha BP, Sandip BP, Nilofar SN (2011) Evaluation of antitumour and antioxidant activity of Earlish ascites carcinoma induced mice. Vitis vinifera L 3(3): 67-72.

17. McLiman WF, Daris EV, Dluver FL, Rake GW (1957) The submerged culture of mammalian cells. The spring culture J Immunol 79: 428-433.

18. Reitman S, and Frankel S (1957) A Colorimetric Method for the Determination of Serum Glutamic Oxalacetic and Glutamic Pyruvic Transaminases. American Journal of Clinical Pathology 28: 56-63.

19. Rock RC, Walker WG, Jennings CD (1987) Nitrogen metabolites and renal function. In: Tietz NW (Ed.), Fundamentals of clinical chemistry. 3rd ed. Philadellphia: WB Saunders, pp. 669-704.

20. Putton C, Crouchd S (1977) Determination of serum blood urea nitrogen. Anal Chem: 464-469.

21. Ohkawa H, Onishi N, K Yagi (1979) Assay for lipid peroxidation in animal tissue by thiobarbituric acid reaction. Anal. Biochem 95: 351-358.

22. Cortas NK, Wakid NW (1990) Determination of inorganic nitrate in serum and urine by a kinetic cadmium-reduction method. Clin Chem 36 : 1440-1443

23. Ellman GL (1979) Tissue sulphydryl groups. Arch Biochem Biophys 82 70-77.

24. Ambriz-Aviña V, Contreras-Garduño JA, Pedraza-Reyes M (2014) Applications of flow cytometry to characterize bacterial physiological responses. BioMed research international 461941-461941.

25. Finney DJ (1964) Statistical methods in biological assay" Charles Griffen \& Company Limit, London, pp. 437-445.

26. Amer YE (1986) Studies on the effect of Dietary Magnesium amd manganese on Experimental Tumour Cell (in mice). Thesis, Ain-Shams University, p.35.

27. Dasari S, Tchounwou PB (2014) Cisplatin in cancer therapy: molecular mechanisms of action. European journal of pharmacology 740: 364-378.

28. ShewachDS, Kuchta RD (2009) Introduction to cancer chemotherapeutics. Chemical reviews 109: 2859-2861.

29. Aghajanpour M, Nazer MR, Obeidavi Z, Akbari M, Ezati P, et al. (2017) Functional foods and their role in cancer prevention and health promotion: a comprehensive review. American Journal of Cancer Research 7: 740-769.

30. Peters GJ, van der Wilt CL, van Moorsel CJA, Kroep JR, Bergman AM, et al. (2000) Basis for effective combination cancer chemotherapy with antimetabolites. Pharmacology \& Therapeutics 87: 227-253.

31. Yerra R, Malaya G, Upal K (2005) Antitumor and in vivo antioxidant activity of Mucuna pruriens. IJPT 4: 46-53.

32. Johnston DE (1999) Special considerations in interpreting liver function tests. Am Fam Physician 59: 2223-2230.

33. Patel NH, Condron BG, Zinn K (1994) Pair-rule expression patterns of even-skipped are found in both short- and long-germ beetles. Nature 367: 429-434

34. Dar S, Nautiyal V, Phulia V, Bhat I, Srivastava P, et al. (2017) Determination of benzimidazoles in fish plasma by chromatographic method and their effects on metabolic and antioxidative enzymes activity. Aquaculture 486: $57-63$

35. Zahran FM, FF Abdel-Latif, AR Sayed, Rabab Shaban, Akaber T Keshta (2013) Biological study of the effect of some new synthetic triazol derivatives on Ehrlish Ascitis Carcinoma cells. International journal of Biological \& Pharmacological Research 4(4): 261-270.

36. Langseth L. from the editor (1993) (Langseth, 1993Antioxidants a (Langseth, 1993nd diseases of the brain: Antioxidant vitamin. Newsletters 4: 3 .

37. Mercuri F, quagliaro L, Cerliello A (2000) Oxidative stress evaluation in diabeted. Diabetes Techn Ther 2: 589.

38. Hensley K, Robinson KA, Gabbita SP, Salsman S, Floyd RA (2000) Bioabsorption and in vivo antioxidant properties of grape extract. Free Radic. Biol Med 26: 1456

39. Sinclair AJ, AH Barnett, J Lunie (1990) Free radical and auto-oxidant systems in health and disease. Br J Hosp Med 43: 334-344.

40. Kaynar H, Meral M, Turhan H, Keles M, Celik G, et al. (2005) Glutathione peroxidase, glutathione-S-transferase, catalase, xanthine oxidase, $\mathrm{Cu}$ Zn superoxide dismutase activities, total glutathione, nitric oxide, and malondialdehyde levels in erythrocytes of patients with small cell and non-small cell lung cancer. Cancer Lett 227: 133-139.

41. Girotti AWJ (1998) Lipid Res 39: 1529.

42. Yagi K (1987) Lipid peroxides and human diseases. Chem Phys Lipids 45: 337-351.

43. Kaynar H, Meral M, Turhan H, Keles M, Celik G, et al. (2005) Cancer Lett 227: 133.

44. Badr El-Din NK (2004) Protective role of sanumgerman against y-irradiation-induced oxidative stress in Earlich carcinoma-bearing mice. Nutrition recerch 24: 271-291.

45. Karaali N (2018) Synthesis of Some New Benzimidazole Derivatives Containing Chlorine and Investigation of Their Antioxidant and Antiurease Activities. JOTCSA 5(2): 971-980.

46. Szatrowski TP, Nathan CF (1991) Production of large amounts of hydrogen peroxide by human tumor cells. Cancer Res 51: 794-808.

47. Seven A, Civelek S, Inci E, Inci F, Korkut N, et al. (1999) Clin Biochem 32 369.

48. Marnett LJ (1999) Lipid peroxidation-DNA damage by malondialdehyde. Mutat Res 424: 83-95.

49. Muriel P, Sandoval G (2000) Hepatic basolateral plasma high-affinity Ca2+-ATPase is inhibited by nitric oxide and peroxynitrite anion. J Appl Toxicol 20: 425-439.

50. Ahmed HH, Hamza AH, Shalby AB (2010) Australian Journal of Basic and Applied Sciences 4: 6359.

51. Ohshima H, Bartsch H (1994) Chronic infections and inflammatory processes as cancer risk factors: possible role of nitric oxide in carcinogenesis. Mutat Res 305: 253. 
52. Eijan AM, Piccardo I, Riveros MD, Sandes EO, Porcella H, et al. (2002) Surg Oncol 81: 203.

53. Taysi S, Koc M, Buyukokuroglu ME, Altinkaynak K, Sahin YNJ (2003) Pineal Res 34: 173

54. Haklar G, Sayin-Ozveri E, Yuksel M, Aktan AO, Yalcin AS (2001) Cancer Lett 165: 219.

55. Kaynar H, Meral M, Turhan H, Keles M, Celik G, et al. (2005) Cancer Lett 227: 133

56. Raso GM, Meli R, Di Carlo G, Pacilio M, Di Carlo R (2001) Life Sci 68: 921.

57. Gu G, Du Y, Hu H, Jin C (2003) Carbohydr. Res 338: 1603.

58. Krajewski S, Tanaka S, Takayama S, Shibler MJ, Fenton W, et al. (1993) Investigations of the subcellular distribution of the Bcl-2 oncoprotein: Residence in the nuclear envelope, endoplasmatic reticulum, and outer mitochondrial membranes. Cancer Res 53: 4701-4714.

59. Valet $G$ (2002) Predictive medicine by cytomics: potential and challenges. J Biol Regul Homeost Agents 16: 164-167.

60. Kluck RM, Bossy-Wetzel E, Green DR, Newmeyer DD (1997) The release of cytochrome c from mitochondria: A primary site for Bcl-2 regulation of apoptosis. Science 275: 1132-1136.

61. Candelaria Gomez-Manzano, Juan Fueyo, Athanassios P Kyritsis, McDonnell TJ, Steck PA, et al. (1997) Characterization of p53 and p21 Functional Interactions in Glioma Cells en Route to Apoptosis. Journal of the National Cancer Institute 89(14): 1036-44.
62. Tominaga O, Hammel P, Hamelin R, Nagawa H, Muto T, et al. (1998) Quantification and characterization of total cellular p53 protein in colorectal cancer. Cytometry 31: 60-66.

63. Maung ZT, MacLean FR, Reid MM, Pearson AD, Proctor SJ, et al. (1994) The relationship between $\mathrm{Bcl}-2$ expression and response to chemotherapy in acute leukemia. Br J Haematol 88: 105-109.

64. Cory S, Adams JM (2002) The Bcl2 family: regulators of the cellular lifeor-death switch. Nat Rev Cancer 2: 647-656.

65. Yousra M El-Far, Khaled H Abd El Galil, Mahmoud M Gabr, Laila A Eissa Mamdouh M El Shishtawy (2013) Antitumor effect of Chitosan and Silibinin and their combination in mice bearing Ehrlich ascites tumors: Impact of p53 and p21. Current Topics Biochemical Research 15: 1.

66. Yang SS, Huang CC, Chen JR, Chiu CL, Shieh MJ, et al. (2005) Effects of ethanol on antioxidant capacity in isolated rat hepatocytes. World J Gastroenterol 11: 7272-7276.

67. Watson JD (2011) Curing incurable Cancer. American Association for Cancer Research 477-480.

68. Lewis R (2011) Triazole Adverse Effects, Toxicity, and Safety. Clinical Primer. 